José G. Merino, MD, MPhil, Editor-in-Chief, Neurology ${ }^{\circ}$

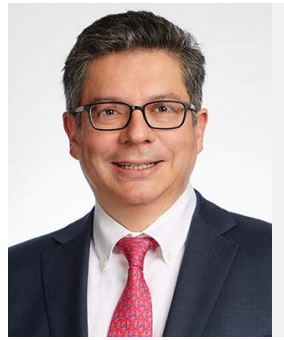

Articles

\section{Patterns of longitudinal cortical atrophy over 3 years in empirically derived MCI subtypes}

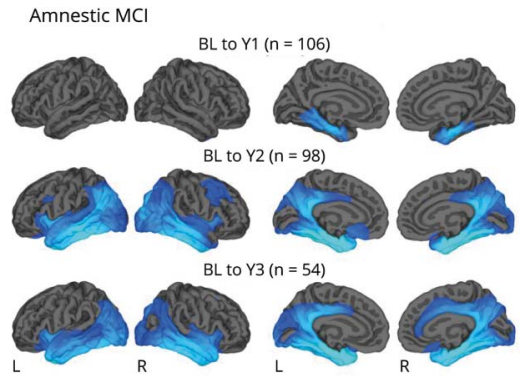

Cognitive subtypes of amnestic mild cognitive impairment (MCI) have unique patterns of longitudinal cortical atrophy over time. These findings highlight the heterogeneity of MCI and show that empirically derived MCI subtypes can reliably reflect underlying atrophy, can reduce false-positive diagnostic errors, and have prognostic value for improving prediction of clinical course.

Page 1067

\section{Distinguishing neurosarcoidosis from multiple sclerosis based on CSF analysis: A retrospective study}

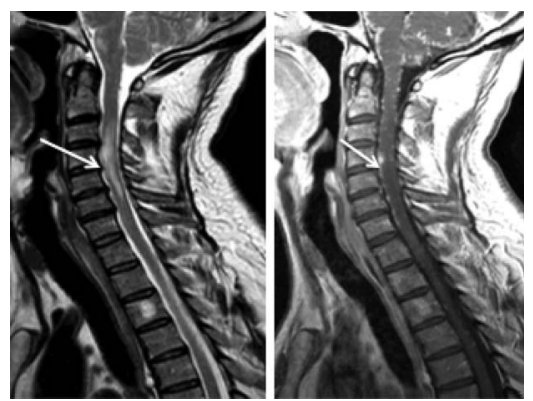

This study of clinical imaging and CSF findings in patients with neurosarcoidosis highlights that the absence of CSF oligoclonal bands is a useful distinguisher from multiple sclerosis and should be considered in future neurosarcoidosis criteria. Elevated white blood cell counts and protein levels, but not CSF angiotensin-converting enzyme levels, may also be supporting criteria.

Page 1068

\title{
Multimodal longitudinal study of structural brain involvement in amyotrophic lateral sclerosis
}

This longitudinal, multimodal imaging study of 292 patients with amyotrophic lateral sclerosis demonstrates progressive cerebral gray and white matter network degeneration. 
Phenotypic variability and C9orf72 genotype correspond to distinct patterns of brain involvement, which is progressive only during the early stage of disease. Monitoring disease progression may be possible through imaging studies, and early intervention may limit cerebral degeneration.

Page 1073

NB: "Reversible brain shrinkage secondary to infant salt toxicity," p. 1103. To check out other NeuroImages, point your browser to Neurology.org/N. At the end of the issue, check out the Resident \& Fellow Section Pearls \& Oy-sters article discussing a case of status epilepticus due to pyridoxine deficiency in a patient with Parkinson disease. This week also includes a Clinical/ Scientific Note titled "Neurologic manifestations in an infant with COVID-19."

\section{NEW EPISODE}

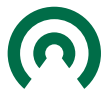

$\underset{\text { PODAST }}{\text { Neurology }}$

June 16, 2020

CME Opportunity: Listen to this week's Neurology Podcast and earn 0.5 AMA PRA Category 1 CME Credits ${ }^{\mathrm{TM}}$ by answering the multiple-choice questions in the online Podcast quiz.

\section{Distinguishing neurosarcoidosis from multiple scle- rosis based on CSF analysis: A retrospective study (see p. 1068)}

1. Distinguishing neurosarcoidosis from multiple sclerosis based on CSF analysis: A retrospective study

2. What's Trending: Personalized iPSC-Derived Dopamine Progenitor Cells for Parkinson's Disease

In the first segment, Dr. David Lapides talks with Dr. Tarunya Arun about her paper discussing diagnosis of neurosarcoidosis. In the second part of the podcast, Dr. Jeffrey Ratliff talks with Dr. Jeffrey Schweitzer about his NEJM paper discussing progenitor cells for Parkinson disease. Read the NEJM article here: https://bit.ly/2XjHvuc.

Disclosures can be found at Neurology.org. 


\section{Neurology}

\section{Spotlight on the June 16 issue}

José G. Merino

Neurology 2020;94;1053-1054

DOI 10.1212/WNL.0000000000009679

\section{This information is current as of June 15, 2020}

\section{Updated Information \&} Services

Permissions \& Licensing

\section{Reprints}

including high resolution figures, can be found at: http://n.neurology.org/content/94/24/1053.full

Information about reproducing this article in parts (figures,tables) or in its entirety can be found online at:

http://www.neurology.org/about/about_the_journal\#permissions

Information about ordering reprints can be found online:

http://n.neurology.org/subscribers/advertise

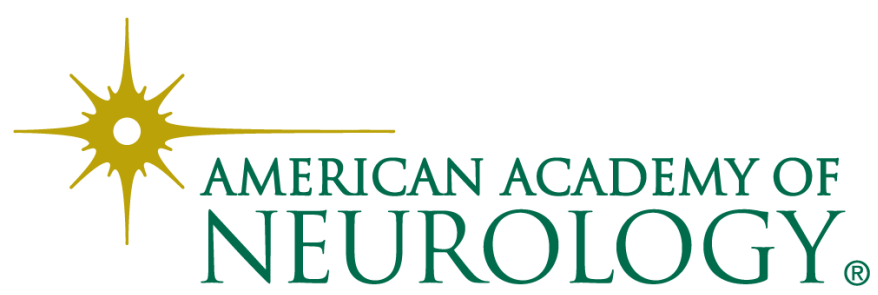

